\title{
Besearch S Surare \\ Probing the gut microbiome of migratory birds for antibiotic resistance genes
}

\section{Jian Cao}

Yongfei Hu

Fei Liu

Yanan Wang

Yuhai Bi

$\mathrm{Na} \mathrm{LV}$

Jing Li

Baoli Zhu

George Fu Gao

\section{Video Byte}

Keywords: migration, migratory birds, gut microbiome, antibiotic resistance, resistant infections, bacteria, China, genetic analysis, tetracycline, aminoglycoside, $\beta$-lactam, sulfonamide, transmission, Microbiome

Posted Date: October 28th, 2020

DOI: https://doi.org/10.21203/rs.3.rs-99177/v1

License: (9) This work is licensed under a Creative Commons Attribution 4.0 International License. Read Full License 


\section{Abstract}

Antibiotic resistance is a growing public health problem. By the year 2050, more than 10 million people are expected to die from resistant infections. How are researchers tackling that problem? One team is looking at the gut bacteria found in migratory birds. Migratory birds acquire and spread antibacterial resistance genes from their environment with the gut microbiome, serving as a reservoir for these insidious genes. To understand the role of the gut microbiome, researchers gathered fecal samples from migratory birds and their favorite landing spots in China. Genetic analysis revealed 1030 distinct genes conferring resistance to antibiotics including tetracycline, aminoglycoside, $\beta$-lactam, and sulfonamide. While the microbes detected in the guts of birds were less diverse than those found in their surroundings, birds carried a greater number of antibiotic resistance genes. These findings encourage closer surveillance of antibiotic resistance genes in migratory birds, which could help prevent the rampant transmission of antibiotic resistance to humans and other animals. 